\title{
How partnerships shaped the Dane CARES farm-to-food bank program
}

\author{
Jessica Guffey Calkins ${ }^{a}$ and Claire Mance ${ }^{b}$ \\ University of Wisconsin-Madison Extension Dane County
}

Submitted January 29, 2021 / Published online September 16, 2021

Citation: Guffey Calkins, J., \& Mance, C. (2021). How partnerships shaped the Dane CARES farm-

to-food bank program. Journal of Agriculture, Food Systems, and Community Development, 10(4), 33-36.

https://doi.org/10.5304/jafscd.2021.104.023

Copyright (C) 2021 by the Authors. Published by the Lyson Center for Civic Agriculture and Food Systems. Open access under CC-BY license.

\begin{abstract}
The COVID-19 pandemic forced Wisconsin's food systems institutions into rapid innovation as they responded to rising community food insecurity. With support from the Dane County Executive's office, federal relief funding eased previously onerous barriers to allow Dane County's largest food bank to implement a unique local purchasing program: Dane CARES. The program sought to support Dane County producers experiencing reductions in market opportunities, while feeding the rising number of Dane County families experiencing food hardship. Drawing on existing food and agriculture partnerships, Extension Dane County staff connected partners to assist with project expedition and documented partners' efforts through a series of semistructured interviews. The program achieved its two primary goals of replacing lost markets for local farmers and facilitating increased food distribution to communities in need. To elevate this multisector collaboration and inspire more great work like Dane CARES, we outline the evidence of program value to farmers' livelihoods, demonstrate the growth of partner networks to support institutional purchasing of local food, and offer recommendations to improve future program iterations.

\section{Keywords}

CARES Act, Collaboration, COVID-19, Emergency Food, Extension, Farmers, Food Bank, Food Pantries, Food Security, Pandemic

\footnotetext{
a* Corresponding author: Jessica Guffey Calkins, Community Food Systems Educator, Community Food Systems Program, Community Development Institute, University of Wisconsin-Madison Extension Dane County; 5201 Fen Oak Drive, Suite 138; Madison, WI 53718 USA; calkins.jessica@,countyofdane.com

${ }^{\mathrm{b}}$ Claire Mance, Healthy Communities Coordinator, FoodWIse Program, Health \& Well-Being Institute, University of WisconsinMadison Extension Dane County; 5201 Fen Oak Drive, Suite 138; Madison, WI 53718 USA; mance.claire@,countyofdane.com
} 


\section{Background}

Wisconsin is known for its rich agricultural history. Dane County is home to the largest producer-only farmers market in the United States, which can draw tens of thousands of visitors, as well as local chefs, each week to Madison's Capitol Square to support its 150-170 vendors. In 2017, the county's 2,566 farms earned it a ranking of 97th among the 3,077 counties nationwide when comparing market value of agricultural products sold (U.S. Department of Agriculture [USDA] National Agricultural Statistics Service, 2017). Despite rich production statistics, more than 43 food pantries serve the $12 \%$ of Dane County residents experiencing food insecurity, 18.8\% of whom are children (Public Health Madison Dane County, 2020; Wisconsin Food Security Project, 2020).

As the COVID-19 pandemic crept into communities across the U.S. in the spring of 2020, food insecurity rates increased, and institutions such as farmers markets, school meal services, restaurants, and emergency food centers were forced into a process of rapid innovation. With support from the Dane County Executive's office and eight million dollars in federal Coronavirus Aid, Relief, and Economic Security (CARES) Act funding, Second Harvest Food Bank of Southern Wisconsin embarked on a local purchasing program for the first time. Funding allowed the food bank to tap into the local food supply chain during a time of reduced donations and national supply chain shortages. It simultaneously secured support for Dane County producers experiencing reductions in market opportunities, while feeding the rising number of Dane County families experiencing food insecurity.

The emergency food system, while intended to provide short-term assistance during heightened times of need, has become a resource many people regularly rely on to meet their nutrition needs. Emergency food provides critical relief to stave off food insecurity, but has limited capacity in addressing the root causes of hunger or poverty. System-level change to address food insecurity requires innovative partnerships and reimagining the role of emergency food. Farm-to-food bank models have been successful in communities across the country. Dane County is unique in that it is highly agriculturally productive and the second most densely populated county in Wisconsin. Food system partners were highly encouraged to see an effort to connect growers and eaters in need at this scale, but it would be a huge undertaking. This was a first-of-its-kind project for Second Harvest, and implementation would begin within four short weeks of receiving federal funding.

\section{Facilitating Connections}

Prior to the Dane CARES project, Second Harvest faced onerous barriers to purchasing local food, despite seeing the value in it-barriers related to aggregation needs and adherence to donor expectations of meal equivalencies. The Dane CARES funding removed the purchasing cost barrier; the next step was to build out connections and systems.

Through a long history of collaborating on county-based food projects, Extension Dane County (a division of University of Wisconsin-Madison) has deep relationships with its food and agriculture partners, as well as a strong interest in connecting local food to Dane County residents and filling in food systems gaps. Extension has a primary role in the community to connect and convene partners. Subsequently, colleagues from Extension Dane County facilitated introductions between Second Harvest and a small group of local food experts to assist with expediting the project. These food experts included food advocacy nonprofits, farmers and produce aggregators, farmers market managers, and food pantry directors. Considering the depth of experience across these organizations and a strong will to see our food systems put to good use, these partners were well poised to collaborate on groundbreaking work.

Through a series of meetings, local food experts mentioned above provided invaluable information to the food bank about the inner workings of small farms, especially produce growers. Topics included planting and harvesting schedules, storage, delivery, farmers' use of technology, and language limitations. 
They shared suggestions about software and ordering processes to employ, and provided critical insight about communication strategies, explaining the diverse set of circumstances in which farmers live and work. Importantly, this group of local food experts provided key contacts to produce aggregators that, in one case, expedited and streamlined purchasing from 24 farms. This was a major success from those initial conversations, and one that served to launch the procurement of local produce.

Among the many other partnerships that were formed to advance this project was one with Epic, a healthcare software company whose large campus was vacant due to remote work necessitated by the COVID-19 pandemic. Epic generously made available its kitchen facilities and pivoted its culinary staff to prepare, pack, and store CARES project food boxes for Second Harvest. Once the boxes were prepared, Second Harvest's network of dedicated food pantries allowed for streamlined distribution of the local produce, meat, and dairy products to families and individuals in need.

The enormity of this effort cannot be understated. Second Harvest Food Bank of Southern Wisconsin serves 16 counties, while the CARES funding supported Dane County only. Creating a new system that must function separately from typical operations is no simple task, but it serves as proof of what is possible when partners collaborate across sectors. The sustainability of this model could serve as a critical element in supporting a strong and resilient regional food system.

\section{Evaluating Partner Impact and the Growth of New Relationships}

Extension Dane County sought to elevate the story of this multisector collaboration and in turn, inspire more great work like this locally and around the state. To capture the experiences of the partners involved in this program, Extension Dane County colleagues conducted seven semistructured interviews with 12 partners. Interviewees included leadership from the food bank, a produce aggregator, executive directors from three local food nonprofits, a group of food pantry directors, and a farmer.

The aim of the interviews was to glean insights from their experiences to:

1. Gather evidence of the program's value to farmers' livelihoods in a time of crisis (this value would provide a case for the continuation of this program);

2. Demonstrate the growth of partner networks to support institutional purchasing of local food; and

3. Offer recommendations to improve future program iterations via increased stakeholder input.

This program was very successful in its two primary goals of replacing lost markets for local farmers and facilitating increased food distribution to address elevated food insecurity caused by the pandemic. A big development is that Second Harvest now has gained in-depth experience in local food purchasing-it has established relationships among produce growers and aggregators, cheesemakers, and dairy and livestock farmers. Second Harvest has also increased knowledge about managing federal funding, with systems in place to accommodate future federal funding to allow increased flexibility for local purchasing. Furthermore, some food pantries report building new relationships with farmers themselves. After months of accepting deliveries, the food pantries and the farms have a direct line to one another as an additional marketplace.

As with any new program, and especially one initiated on extremely short notice, there are areas of opportunity for future program growth and sustainability. Partners provided suggestions about how lines of communication could be strengthened and expanded. This could also entail food banks hiring someone with experience in food and farming, with specific experience dealing with seasonality, perishability, and post-harvest handling of crops. Doing so would streamline purchases, promote communication with farmers regarding planting and harvest schedules, and reduce potential waste. 
Another consideration is to hire someone to give direct support to producers whose primary language is not English and/or to those with less technology proficiency. Dane County is home to a community of Hmong growers, 16 of whom vend at the Dane County Farmers' Market. If additional resources could be allocated, a greater diversity of local growers would be able to participate in the CARES program.

\section{Conclusion}

This pilot program laid important groundwork in relationship-building and creating systems that might not have come to fruition without the urgency of emergency circumstances. Partners expressed sincere appreciation for Dane County leadership in their decision to fund a farm-to-food bank project that was a clear win-win for both producers and families in need. Likewise, partners lauded Second Harvest for going above and beyond to serve as a mechanism to turn the idea into reality. The CARES project was a considerable undertaking, and several interviewees described Second Harvest's work as "nothing short of a miracle" given the time constraints, infrastructure challenges, and new territory of local purchasing. This effort could not have been successful without the many stakeholders who offered advice, facilitated connections, and worked within their own networks to streamline ordering.

Through this program, Second Harvest gained cross-sector connections which have had a valuable effect in bringing together disparate players in the local food system to the same table. Second Harvest staff expressed an interest in working to keep open the doors to other food sources in order to continue and build upon the progress and new relationships established.

Community investment in local agriculture and its subsequent linkage to the emergency food system can reshape how we think about addressing food insecurity. This farm-to-food bank project is further evidence that there is no single mechanism for supporting healthy communities. Yes, food is a tangible good, but it can also be used to represent a force for stability, dignity, and support.

\section{Acknowledgments}

We appreciate the contributions to this work from the following: Badger Prairie Needs Network, Crossroads Community Farm, Dane County Executive's Office, Dane County Farmers' Market, FairShare CSA Coalition, FarWell, Garden To Be, Middleton Outreach Ministry, REAP Food Group, The River Food Pantry, Rooted, and Second Harvest Food Bank of Southern Wisconsin.

\section{References}

Public Health Madison Dane County. (2020). Madison \& Dane County Food Resources 2020. http://www.publichealthmdc.com/documents $/ 2020 \% 20$ food $\% 20$ resource $\% 20$ guide-eng.pdf

U.S. Department of Agriculture [USDA] National Agricultural Statistics Service. (2017). 2017 Census of Agriculture County Profile: Dane County, Wisconsin. https://www.nass.usda.gov/Publications/AgCensus/2017/Online Resources/County Profiles/Wisconsin/cp5502 5.pdf

Wisconsin Food Security Project. (n.d.). Wisconsin Food Security Project profiles [Data file]. Retrieved December 2020 from http:// foodsecurity.wisc.edu/profiles 